\title{
Visões marxistas nos estudos inter-raciais
}

\author{
Tristan Castro-Pozo
}

Neste trabalho o intento é abordar a relação entre o materialismo dialético e as teorias raciais nos círculos intelectuais e ativistas dos negros. O interesse em discutir o tema surgiu a partir de leituras e experiências com o marxismo, contra as quais percebi haver uma "criação de anticorpos" entre líderes do movimento negro. Assim, vou restringir a reflexão sobre o tema aos fatores socioculturais e econômicos, mas sem a ambição de fazer uma cronologia dos diversos enfoques em que transitam as teorias de raça.

Ao final de século XIX, o enfoque evolucionista exerceu forte influência nas ciências sociais, uma aproximação que foi denominada darwinismo social. O modelo evolucionista marcou o conceito de tipologia racial permanente, porquanto a teoria da seleção natural iluminava novos enfoques para as teorias raciais. As duas leis de Darwin sobre "a origem das espécies" - seleção natural e sobrevivência do mais adaptado - deram uma justificativa para as crenças na superioridade racial, para as práticas sexistas e para a "imoralidade" cometida pelo capitalismo².

O materialismo dialético formulou conceitos de caráter histórico e econômico se baseando nas leis do evolucionismo. Um trabalho que pontua o fazer pré-produtivo hominídeo, trazendo embasamento nas premissas evolucionistas, é "o papel do tra-

1 Doutorando CCA - ECA - USP.

2 Michael Ruse, The Darwin Paradgm. NJ, Routledge, 1989, p. 157.

38 Visões marxistas nos estudos inter-raciais 
balho na humanização do macaco" de Friedrich Engels. Ele faz referência à diáspora atlântica negra como uma fase regressiva para o pensamento humano: os homens saíam do obscurantismo religioso e iniciavam a produção dos clássicos das línguas românicas, mas esse processo se estagnou devido às práticas escravocratas ${ }^{3}$.

Séculos sucessivos de exploração colonial instauraram o racismo de cor, deixando o legado de um sistema de dominação cultural que sobreviveu ao regime colonialista. Nessa transição no discurso hegemônico colonial surgiu o movimento de negritude, o qual advoga pelo retorno à cultura autóctone e popular. Zilá Bernd estabelece um paralelo entre o movimento de negritude como um despertar da consciência racial e o "indigenismo", que paralelamente tentava revalorizar os componentes folclóricos e comunitários como uma via para a geração de um salto desenvolvimentista. Segundo Z. Bernd, ambos os movimentos foram salientados pelo movimento comunista internacional, que pregava uma sociedade sem classes e sem discriminação raci$\mathrm{al}^{4}$. O enfoque marxista acreditava na hipótese de que, mediante o despertar de uma consciência de raça negra, posteriormente se operaria o trânsito para a consciência de classe e a conseqüente identificação das múltiplas opressões ${ }^{5}$.

No mesmo plano teórico, Frantz Fanon define a negritude como a antítese do comportamento racista, ou seja, é através da negritude que o sujeito negro compreende os mecanismos de inferiorizarão que a sociedade exerce contra si ${ }^{6}$. F. Fanon acredita numa negritude como sendo a expressão máxima da luta pelos direitos civis do negro, pelo direito a assumir a sua identidade cultural e pela reivindicação de uma agenda de combate pela independência cultural.

Oliver Cox desenvolve a tese de que há similaridades entre racismo contra negros nos EUA e o fascismo Europeu. O. Cox conclui que o fascismo representa um setor da economia que precisa do discurso da superioridade racial ${ }^{7}$. O escritor Langston Hughes acreditava que os negros representam uma ameaça para o corporativismo fascista, que veria em risco a sua hegemonia ${ }^{8}$. Também é preciso

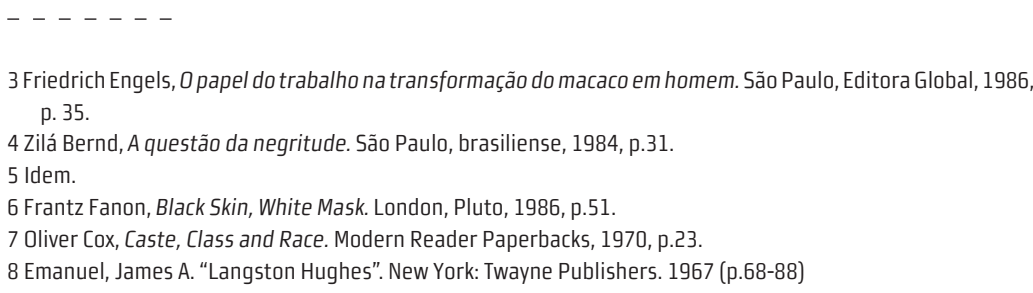

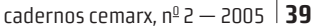


lembrar a atualidade da doutrina Monroe e do macarthismo, que consolidaram o intervencionismo americano baseado não só nas bases militares despregadas pelo mundo todo, mas no reforço de estereótipos raciais veiculados pela mídia contra os orientais, árabes e negros.

Apesar de o marxismo representar uma alternativa contra-hegemônica, o receio de ser tachado de "vermelho perigoso" encontra-se similarmente no penúltimo discurso do reverendo Martin Luther King, em agosto de 1967. Na ocasião ele se refere às tensões em Cuba e ao fato dele não tomar partido pelo comunismo. Luther King acredita que o poder negro vai além do materialismo dialético, pois para ele o marxismo interpretou mal as idéias de Hegel, apropriando-se da dialética, mas deixando de fora o idealismo e o espiritualismo. Assim, o marxismo perdeu de vista que a vida é um fato individual, assim como o capitalismo perdeu a vida como um fato social. Finalmente, Luther King propõe um reino de irmandades que seria formado pela síntese dos fatores sociais, os problemas da discriminação racial, da exploração econômica e os conflitos bélicos, todos interligados.

Nesse penúltimo discurso, Luther King mostra-se conciliador com o fascismo norte-americano, não entendendo que a revolução cubana seria a libertação da população negra cubana do racismo de tradição hispânica. Também Luther King, ao rejeitar a práxis marxista, era pouco visionário em relação aos movimentos revolucionários negros que o sucederam nos inícios dos anos 1970, como "black panthers" ou "black liberation theology".

Paralelamente à adesão ou rejeição dos movimentos negros ao discurso marxista, surgem polêmicas em torno do sistema de estratificação social nos contatos inter-raciais. Gunar Myrdal, no livro O dilema americano, interpretava que a raiz do problema racial residia no confronto entre classes e na situação de pobreza, e não só na discriminação pela cor. Assim, a estratificação das populações negras e brancas corresponde ao sistema de castas, tanto quanto a estratificação num sistema de classes ${ }^{10}$. O sociólogo militante Florestan Fernandes, no livro "O negro no mundo dos brancos", entendia o conceito de classe como um conjunto de relações sociais que definem uma posição objetiva na sociedade; que aquelas rela-

$---{ }_{--1}$

9 Martin Luther King, A Call to Conscience: The Landmark Speeches of Martin Luther King, Jr., Clay Carson Ed., 2001.

10 Gunnar Myrdal, American Dilemma. New York, Harper\&bros, 1944.

40 Visões marxistas nos estudos inter-raciais 
ções e essas posições não são fixas e imutáveis, pois se transformam com a transformação histórica da organização da produção ${ }^{11}$. F. Fernandes propõe a tese de uma "segunda abolição", assinalando que as condições de vida do sub-proletário negro não eram as de uma igualdade constitucional, e que nunca se tinha produzido a passagem do escravo ao cidadão ${ }^{12}$.

Guerreiro Ramos, no texto intitulado "Documentos para uma sociologia militante"13, explora a maiêutica das teorias raciais, ao assinalar que há uma distância entre o tema do negro e a vida do negro (p. 171). O negro como tema é o objeto de literatos, sociólogos e antropólogos, mas o negro como uma realidade afetiva se faz a si próprio. Segundo Guerreiro Ramos, a atitude de formalização diante do negro conduz a apreciações irreais devido à perda de atualidade dos estudos, à contradição entre idéias e os fatos das relações inter-raciais, e pela "patologia do embranquecimento como critério de estética social" (p.172).

Os estudos inter-raciais foram desvendados pela aplicação de categorias marxistas, e logo pelo uso de categorias sensíveis às complexas realidades latino-americanas e pós-coloniais. Assim, terminologias híbridas como "patologia social de embranquecimento" e "democracia racial" dão conta do conhecimento naquilo que é a aparência, mas num fundo misturado e contraditório.

A constatação das similaridades e diferenças nas pesquisas acadêmicas sobre os movimentos negros na América do Norte, o Caribe e América Latina é objeto do livro de Kim Butler "Liberdade entregue, liberdade ganha". Nele a autora discute como a abolição instaurou uma "liberdade falsa", pois as formas de opressão resultantes da diáspora afro-atlântica, desenvolveram-se de formas similares, sendo combatidas por estratégias políticas de afro-descendentes no período de transição da escravidão ${ }^{14}$. Para K. Butler o legado escravocrata é sucedido por um período em que a luta do povo negro se conecta mundialmente através de respostas como a busca de identidades, aculturações e separatismos ${ }^{15}$.

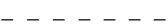

11 Florestan Fernandes, A integração do negro na sociedade de classes. São Paulo, Nacional, 1965, p.69. 12 Idem, p.99.

13 Ramos, Alberto Guerreiro. “Documentos para uma sociologia militante". In: Introdução crítica à sociologia brasileira. RJ: Andes, 1957, (p. 171-216)

14 Kim Butler, Freedoms Given, Freedoms Won: Afro-brazilians in post-abolition São Paulo, Salvador. New Brunswick, NJ, Routledge Press, 1988, p.217. 15 Idem.

cadernos cemarx, $n^{0}-2-2005 \quad \mathbf{4 1}$ 
Perante os estudos comparativos e os modelos de intervenção, atualmente o discurso do marxismo parece querer forçar a realidade mediante o antigo discurso da luta de classes. Mas a própria realidade revela como a "imoralidade do capitalismo" continua reproduzindo um sub-proletariado negro, e que os avanços legislativos se confrontam com a debilidade das instituições para aplicá-los. Assim, pode-se concluir que não existe uma contradição direta entre marxismo e anti-racismo, desde que o pesquisador-militante consiga analisar múltiplas fontes e beber de múltiplas tradições. Aliás, foi assim mesmo experimentado nos primórdios do movimento negro no Harlem e em Paris.

42 Visões marxistas nos estudos inter-raciais 